\title{
Counterion-dependent mechanisms of DNA origami nanostructure stabilization revealed by atomistic molecular simulation
}

\section{Citation for published version (APA):}

Roodhuizen, J., Hendrikx, P. J. T. M., Hilbers, P. A. J., de Greef, T., \& Markvoort, B. (2019). Counteriondependent mechanisms of DNA origami nanostructure stabilization revealed by atomistic molecular simulation. ACS Nano, 13(9), 10798-10809. https://doi.org/10.1021/acsnano.9b05650

DOI:

10.1021/acsnano.9b05650

Document status and date:

Published: 10/09/2019

Document Version:

Publisher's PDF, also known as Version of Record (includes final page, issue and volume numbers)

\section{Please check the document version of this publication:}

- A submitted manuscript is the version of the article upon submission and before peer-review. There can be important differences between the submitted version and the official published version of record. People interested in the research are advised to contact the author for the final version of the publication, or visit the DOI to the publisher's website.

- The final author version and the galley proof are versions of the publication after peer review.

- The final published version features the final layout of the paper including the volume, issue and page numbers.

Link to publication

\footnotetext{
General rights

- You may freely distribute the URL identifying the publication in the public portal. follow below link for the End User Agreement:

www.tue.nl/taverne

\section{Take down policy}

If you believe that this document breaches copyright please contact us at:

openaccess@tue.nl

providing details and we will investigate your claim.
}

Copyright and moral rights for the publications made accessible in the public portal are retained by the authors and/or other copyright owners and it is a condition of accessing publications that users recognise and abide by the legal requirements associated with these rights.

- Users may download and print one copy of any publication from the public portal for the purpose of private study or research.

- You may not further distribute the material or use it for any profit-making activity or commercial gain

If the publication is distributed under the terms of Article $25 \mathrm{fa}$ of the Dutch Copyright Act, indicated by the "Taverne" license above, please 


\title{
Counterion-Dependent Mechanisms of DNA Origami Nanostructure Stabilization Revealed by Atomistic Molecular Simulation
}

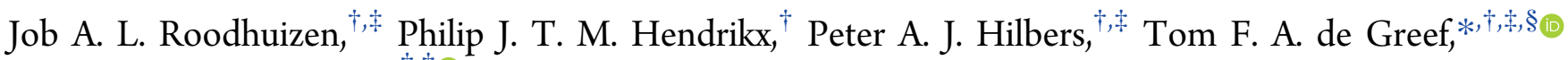 \\ and Albert J. Markvoort $*,+,{ }^{\circ}$
}

${ }^{\dagger}$ Computational Biology Group, Department of Biomedical Engineering and ${ }^{\dagger}$ Institute for Complex Molecular Systems, Department of Biomedical Engineering, Eindhoven University of Technology, P.O. Box 513, 5600 MB Eindhoven, The Netherlands

${ }^{\S}$ Institute for Molecules and Materials, Radboud University, Heyendaalseweg 135, 6525 AJ Nijmegen, The Netherlands

\section{Supporting Information}

ABSTRACT: The DNA origami technique has proven to have tremendous potential for therapeutic and diagnostic applications like drug delivery, but the relatively low concentrations of cations in physiological fluids cause destabilization and degradation of DNA origami constructs preventing in vivo applications. To reveal the mechanisms behind DNA origami stabilization by cations, we performed atomistic molecular dynamics simulations of a DNA origami rectangle in aqueous solvent with varying concentrations of magnesium and sodium as well as polyamines like oligolysine and spermine. We explored the binding of these ions to DNA origami in detail and

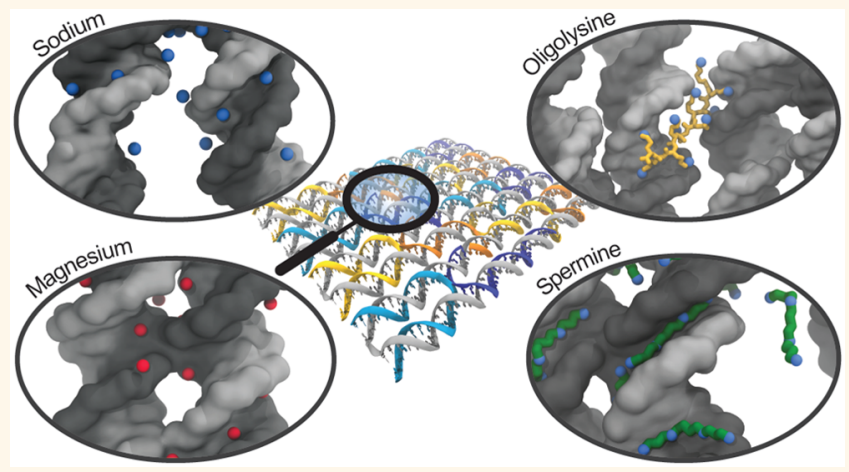
found that the mechanism of stabilization differs between ion types considerably. While sodium binds weakly and quickly exchanges with the solvent, magnesium and spermine bind close to the origami with spermine also located in between helices, stabilizing the crossovers characteristic for DNA origami and reducing repulsion of parallel helices. In contrast, oligolysine of length ten prevents helix repulsion by binding to adjacent helices with its flexible side chains, spanning the gap between the helices. Shorter oligolysine molecules with four subunits are weak stabilizers as they lack both the ability to connect helices and to prevent helix repulsion. This work thus shows how the binding modes of ions influence the stabilization of DNA origami nanostructures on a molecular level.

KEYWORDS: DNA origami, DNA nanotechnology, stability, structural integrity, molecular dynamics, cations

$\mathrm{D}$ NA origami is a robust and reliable method for designing and constructing uniquely addressable DNA-based nanostructures. By exploiting the programmability of Watson-Crick base pairing, circular singlestranded scaffold strands are folded into preprogrammed $2 \mathrm{D}$ or 3D nanostructures using shorter complementary staple strands. ${ }^{1-4}$ Controlled folding is obtained as each staple strand binds to multiple regions of the scaffold strand, forming antiparallel double-stranded DNA (dsDNA) helices interconnected via Holliday junctions or crossovers. Because of their biocompatibility, nontoxicity, ${ }^{5-8}$ and unique addressability, DNA origami structures have been used as drug delivery vehicles, ${ }^{7,910}$ artificial lipid membrane channels, ${ }^{11,12}$ and as a molecular breadboard for enzymatic and chemical reactions. $^{13,14}$ A recent demonstration of the possibilities of DNA origami is the "inside-out virus", a hollow DNA assembly containing proteins that are released upon transfection into HeLa cells. ${ }^{15}$

Although the above examples show the potential of DNA origami in nanomedicine and synthetic biology, applicability is impaired by the lack of structural integrity of DNA origami nanostructures in biologically relevant environments. There are two main reasons for this instability that hinder application of DNA origami nanostructures for biomedical objectives. First, nucleases present in biological environments degrade DNA nanostructures with, depending on the exact design, half-lives in the order of hours to days. ${ }^{16-18}$ Second, DNA origami comprises a high density of negatively charged phosphates on the DNA backbone. Though the stability of DNA origami has

Received: July 18, 2019

Accepted: September 9, 2019

Published: September 10, 2019 

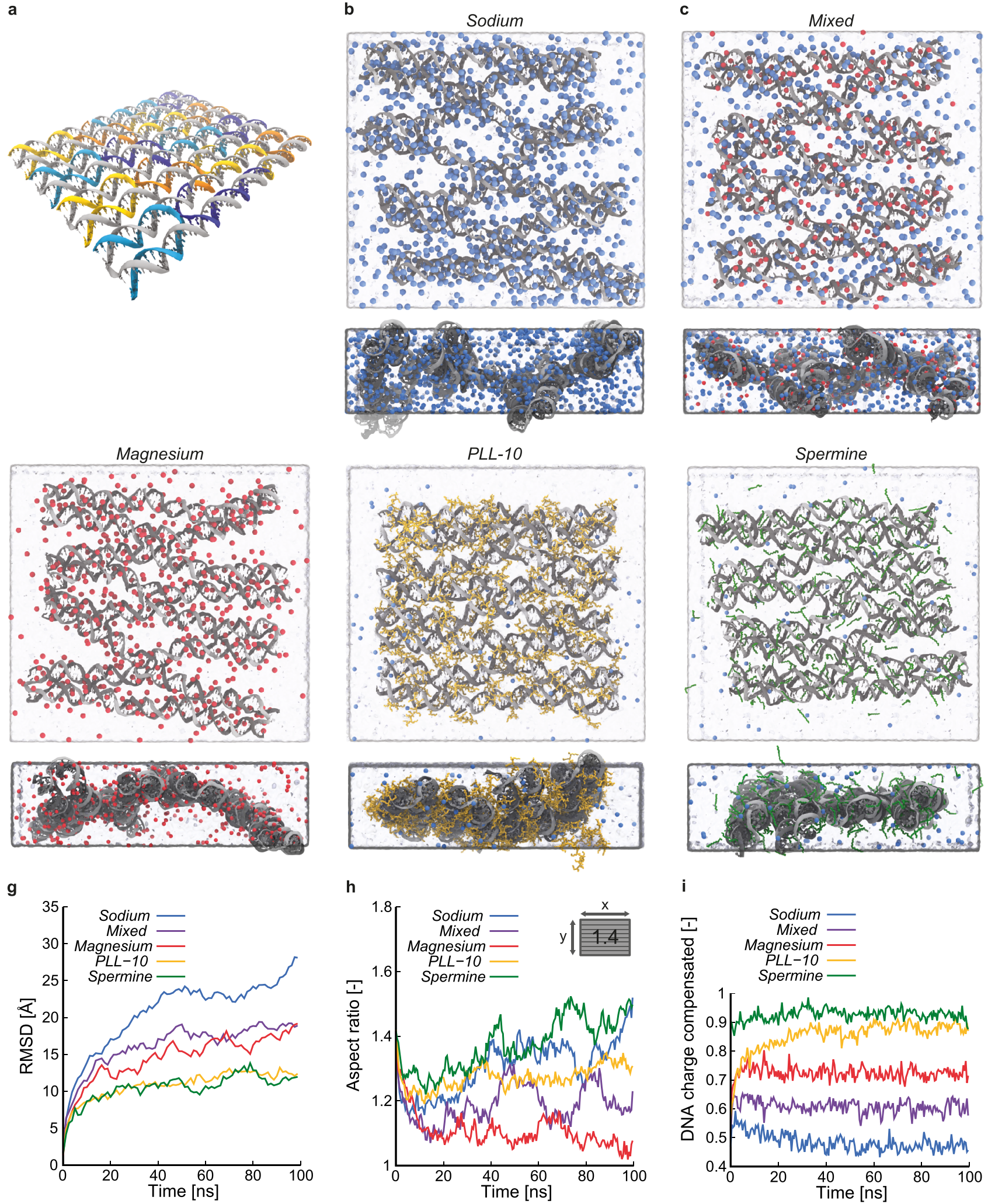

Figure 1. Overview of the DNA origami rectangle and atomistic MD simulations with various counterions. (a) DNA origami design considered in the MD simulations, with the scaffold strand shown in gray and the staple strands in color. (b-f) Snapshots of the final configurations of the Sodium, Mixed, Magnesium, PLL-10, and Spermine simulation, respectively, with the DNA origami shown in gray, water in light blue, and $\mathrm{Na}^{+}, \mathrm{Mg}^{2+}, \mathrm{K}_{10}$, and $\mathrm{Spm}^{4+}$ in blue, red, yellow, and green, respectively. For each structure, both a top and side view are shown. (g) Root-mean-square deviation (RMSD) of the DNA backbone atoms from their initial positions as a function of time for the five simulations. (h) Aspect ratio of the DNA origami rectangle as a function of time for the five simulations. The inset shows the initial aspect ratio. (i) Fraction of DNA charge compensated by ions within 5 Å of DNA atoms for the Sodium, Mixed, Magnesium, PLL-10, and Spermine simulations as a function of time. 
been shown to be strongly dependent on the exact design of the origami as well as on the identity of the buffer, ${ }^{19}$ high concentrations of multivalent cations are therefore required to overcome repulsive forces. In in vitro experiments typically 5$20 \mathrm{mM} \mathrm{Mg}^{2+}$ is used, which is an order of magnitude higher than typical in vivo environments. ${ }^{2,20}$

Several solutions to these problems have been proposed including encapsulation of the nanostructure in a lipid bilayer membrane, ${ }^{21}$ design of polyhedral nanostructures that remain stable at lower cation concentrations, ${ }^{22,23}$ and coating DNAbased nanostructures with cationic polyamines like poly(2dimethylaminoethyl methacrylate) (PDMAEMA). ${ }^{24}$ Recently, Ponnuswamy et al. identified poly(L-lysine) $\left(\mathrm{K}_{n}\right)$ with $n$ at least 10 as a particularly stabilizing polyamine for DNA origami in low $\mathrm{Mg}^{2+}$ environments that also provides protection against nucleases when conjugated to polyethylene glycol (PEG). The authors also identified spermine $\left(\mathrm{Spm}^{4+}\right)$ and spermidine as stabilizing polyamines, although these seem to dissociate from the DNA origami over time. ${ }^{25}$ Oligolysine (Figure S1a) has been studied in relation to DNA vectors as it has been proposed as a transfection agent in gene therapy, ${ }^{26,27}$ while $\mathrm{Spm}^{4+}$ (Figure S1b) and spermidine are naturally occurring molecules involved in DNA condensation and cell longevity. $^{28,29}$ Such polyamines and other multivalent cations have been shown to condense double-stranded DNA at certain concentration ranges. ${ }^{30-36}$ Although many studies have been performed on the interaction of DNA with polyamines and $\mathrm{Mg}^{2+}$ and $\mathrm{Na}^{+},{ }^{37-46}$ mechanistic insights into the stabilization of DNA origami and its characteristic crossovers by these cations on a molecular level are still lacking.

Here we present atomistic molecular dynamics (MD) simulations of a 512 base pair DNA origami rectangle with varying concentrations of $\mathrm{Mg}^{2+}$ and $\mathrm{Na}^{+}, \mathrm{K}_{10}$, and $\mathrm{Spm}^{4+}$ and analyze the stability of the DNA nanostructure in these different environments at time scales up to 100 ns. First, we investigate global structural fluctuations of the origami, after which we focus on local fluctuations and base pair integrity. Finally, we zoom in to analyze the binding of individual ions to the DNA origami at atomistic detail, with a special focus on the crossover-junctions that are characteristic for DNA origami. The root-mean-square deviation and aspect ratio of the origami rectangle reveal a large deviation from the initial structure in environments with only $\mathrm{Na}^{+}$. In contrast, structural integrity of the origami is observed in environments with $\mathrm{Mg}^{2+}$, $\mathrm{Spm}^{4+}$, or $\mathrm{K}_{10}$. Analyses of the hydrogen bonding and internal angles reveal that crossovers and nicks are the main hotspots where disruptions of the origami structure occur. We show that $\mathrm{Mg}^{2+}$ resides near the DNA origami for extended periods of time compared to $\mathrm{Na}^{+}$. By aligning a crossover over multiple timesteps, we demonstrate that $\mathrm{Mg}^{2+}$ ions occupy particular locations near the DNA, while $\mathrm{Na}^{+}$ions are more delocalized and at larger distance from the DNA. Although both $\mathrm{K}_{10}$ and $\mathrm{Spm}^{4+}$ effectively stabilize the DNA origami, the underlying mechanisms for these two polyamines differ significantly. While $\mathrm{K}_{10}$ mainly overcomes repulsion between DNA helices by spanning from one helix to another, $\mathrm{Spm}^{4+}$ efficiently screens the charges on the DNA backbone by binding in the grooves of the helices along the phosphate groups as well as in between helices. Compared to $\mathrm{K}_{10}, \mathrm{Spm}^{4+}$ also results in higher amine concentrations near the crossovers, preserving the " $\mathrm{H}$ "conformation of crossovers and planarity of the origami. To test whether the observed mechanistic differences between $\mathrm{Spm}^{4+}$ and $\mathrm{K}_{10}$ depend on their difference in polyvalency, we finally set up one additional simulation containing $\mathrm{K}_{4}$ as counterions. This work thus reveals the differences in the binding modes of these ions to DNA origami and offers insight into DNA origami stabilization on a molecular level: an important prerequisite for biomedical applicability of these versatile nanostructures.

\section{RESULTS AND DISCUSSION}

Simulations. The DNA origami design in our simulations is based on the original 8192 base pair Rothemund rectangle ${ }^{1}$ but comprises a reduced number of 512 base pairs to maintain computational feasibility in the atomistic $\mathrm{MD}$ simulations (Figure 1a). A schematic representation of our model compared to the original Rothemund rectangle, as well as the full DNA sequence, is shown in Figure S2. An atomistic model of the DNA origami was generated and simulated in five aqueous solutions with distinct ionic content, $10 \mathrm{mM} \mathrm{Mg}{ }^{2+}$, which is a typical concentration for in vitro experiments, a mix of $5 \mathrm{mM} \mathrm{Mg}^{2+}$ and $10 \mathrm{mM} \mathrm{Na}^{+}, 20 \mathrm{mM} \mathrm{Na}^{+}, \mathrm{K}_{10}$, and $\mathrm{Spm}^{4+}$. These are denoted as Magnesium, Mixed, Sodium, PLL-10, and Spermine simulation, respectively. The exact content of each simulation is shown in Table S1. We first performed an equilibration protocol in which the positions of DNA origami backbone atoms are held fixed and ions diffuse toward the DNA origami. After the number of ions near the origami stabilized, all constraints were released and $100 \mathrm{~ns} \mathrm{MD}$ production runs were initiated. Simulation details, as well as the methods used for solvation and ionization, are described in the Methods Section. Snapshots of the final configurations of the five systems are shown in Figure $1 \mathrm{~b}-\mathrm{f}$, respectively.

Global Conformational Changes. We first assessed how the different ionic environments affect global deformations of the origami construct. A conventional measure of the global deformations of a structure is the root-mean-square deviation (RMSD). Figure $1 \mathrm{~g}$ shows the RMSD of the DNA origami backbone atoms from their initial positions as a function of time. For all simulations, the RMSD increases during roughly the first half of the trajectory before reaching a plateau. In the Magnesium, Sodium, and Mixed simulations, a trend of decreasing RMSD values with increasing $\mathrm{Mg}^{2+}$ concentration is observed. The Spermine and PLL-10 simulations show similar RMSD values that lie significantly lower than those in the simulations containing $\mathrm{Na}^{+}$and $\mathrm{Mg}^{2+}$. These reduced global fluctuations are consistent with the experimental observation that these multivalent ions are able to stabilize DNA origami structures. ${ }^{25}$ To verify if the simulations reach steady state, we also calculated the RMSD of the backbone atoms from their positions halfway through the simulation (Figure S3), which indicated that after $50 \mathrm{~ns}$, the global conformations of the structures remain largely the same, which made us confident that the time scale of our simulations is sufficiently long.

Since RMSD only shows the average magnitude of deviations from a reference structure, we subsequently explored measures that describe the shape of the origami. As the origami construct is rectangular, an evident measure of the global structure is the aspect ratio, defined as the ratio between the sizes of the origami in the direction of the DNA double helices and in the direction in the origami plane perpendicular to the double helices. In Figure 1h, the aspect ratios of the DNA origami constructs in the five simulations are shown as a function of time. All initial structures, with aspect ratio 1.4, are elongated in the direction along the helices, and all simulations 
a

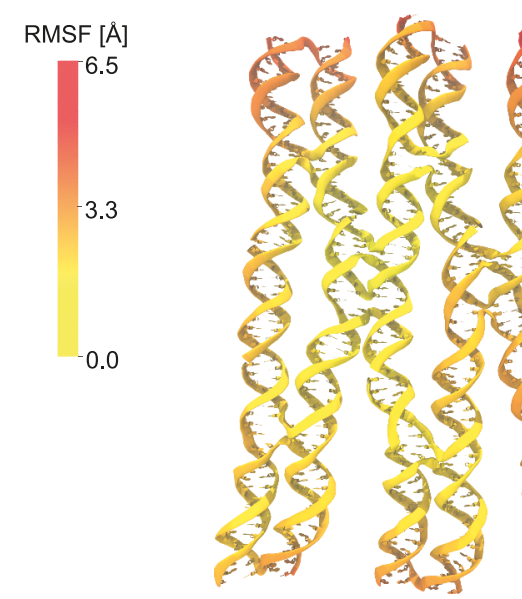

C

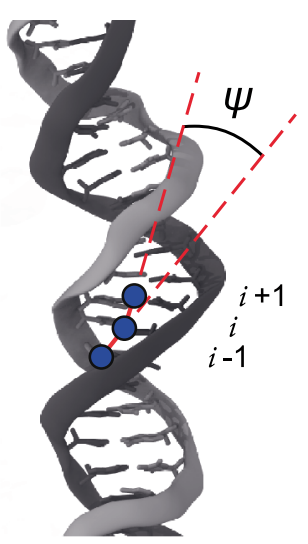

$\mathbf{f}$

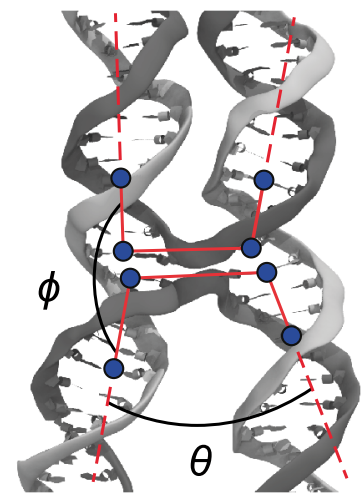

b

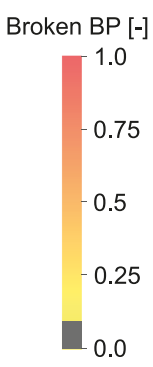

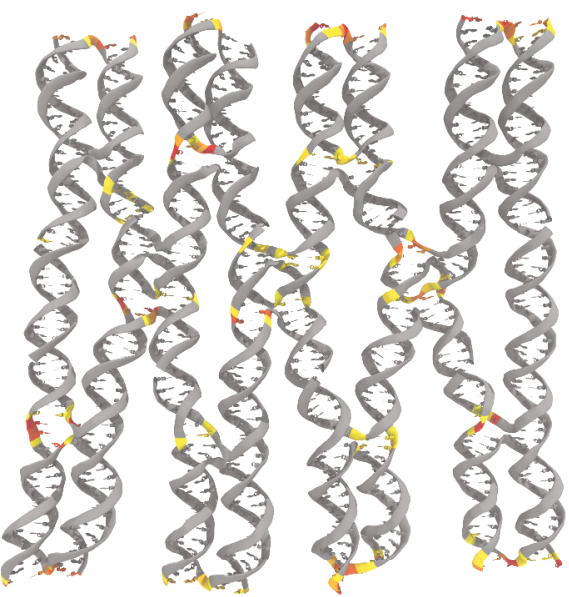

e

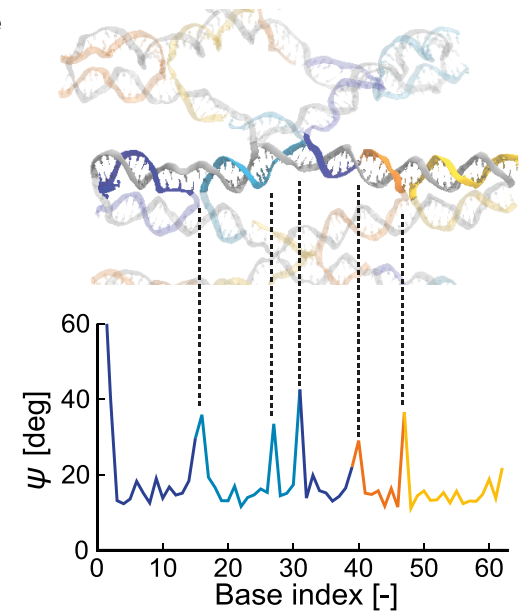

h

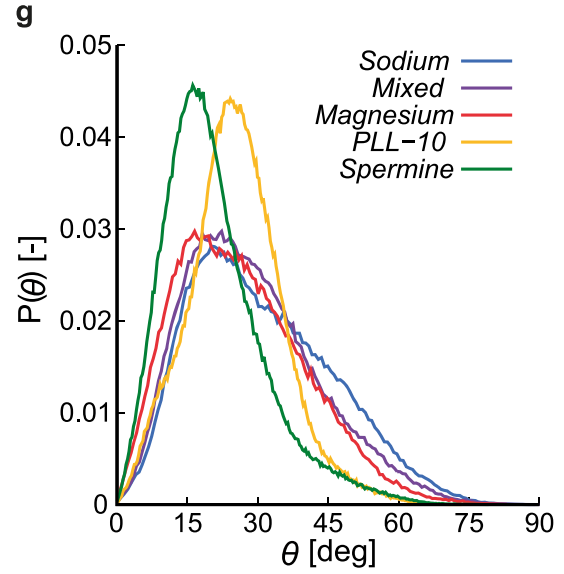

d
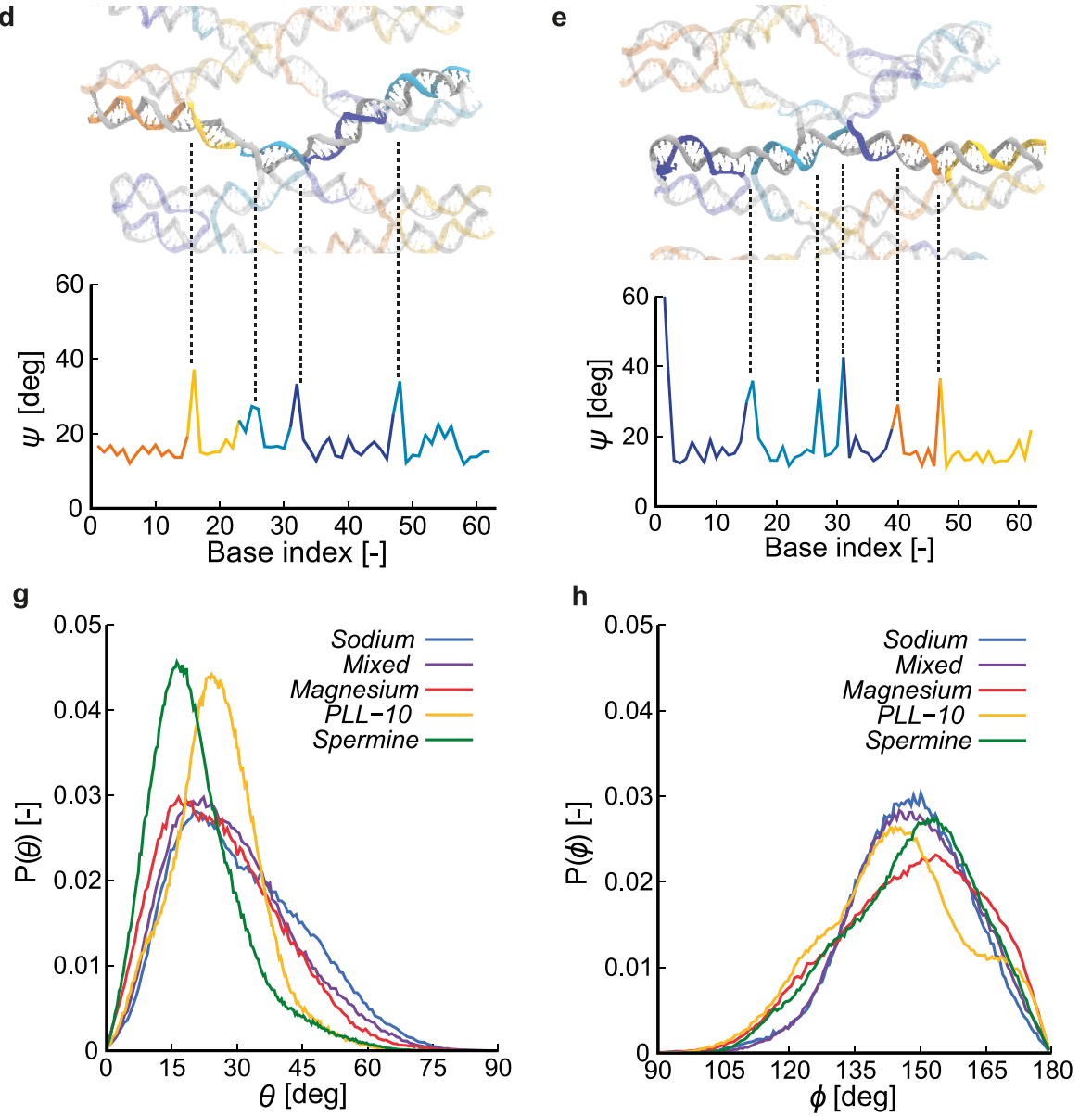

Figure 2. Structural analysis of the DNA origami rectangle. (a) Root-mean-square fluctuations (RMSF) per nucleotide center of mass mapped onto the DNA's time averaged structure for the Magnesium simulation. (b) Fraction of time the base pairs are broken for the Magnesium simulation mapped onto the DNA's time averaged structure. (c) Schematic for the definition of helix angles $\psi_{i}$ for base index $i$. $(\mathrm{d}, \mathrm{e})$ Helix angles $\psi_{i}$ in the Sodium simulation for helices 4 and 5, respectively. (f) Schematic for the definition of crossover angles $\theta$ and $\phi$. (g) Probability distributions of the angle $\theta$ for all five simulations. (h) Probability distributions of the angle $\phi$ for all five simulations.

initially show a decreasing aspect ratio in time. While the aspect ratio in the Magnesium simulation stabilizes at a value approaching that of a square origami, the aspect ratio in the Sodium and Spermine simulations rises again after $25 \mathrm{~ns}$. Visual inspection reveals an expansion of the DNA helices perpendicular to the helices in the Sodium simulation as well as a global twist in the structure of the origami. This causes the origami to deviate from an approximately flat rectangle and to extend over the entire simulation box at the end of the simulation, which renders the description of the structure by the aspect ratio of a $2 \mathrm{D}$ rectangle rather invalid. In contrast, the origami structure in the Spermine simulation becomes more oblong over time. This increase in aspect ratio originates from a closer packing of the helices, which can be attributed to ability of $\mathrm{Spm}^{4+}$ to effectively screen the negative charges on the backbone phosphates causing an attractive force between 
helices. Attraction of parallel DNA helices has been observed in earlier experiments, ${ }^{31-34}$ and the mechanism has been debated for many years, ${ }^{47}$ with attempts to describe this effect using counterion correlation theories like the Wigner crystal model, ${ }^{48-50}$ bridging model, ${ }^{51,52}$ or more recently, an overlapping shell model. ${ }^{53,54}$ It has been established that polyelectrolytes with a charge of at least three are required to observe this behavior. ${ }^{32,55}$ However, whereas these theories are aimed at parallel DNA helices, an essential feature of DNA origami is the connection of helices through Holliday junctionlike crossovers, which we will analyze in detail further. The opposite behavior, that is, the observed expansion of the origami perpendicular to the helical axes in the Magnesium, Mixed, Sodium, and to a smaller extent the PLL-10 simulations can analogously be rationalized by a lower efficiency of the ions in these simulations to screen the electrostatic interactions on the DNA backbone compared to $\mathrm{Spm}^{4+}$, leading to repulsion of neighboring helices and an aspect ratio closer to 1 . This is corroborated by a previous work, where a linear relationship between $\mathrm{Mg}^{2+}$ concentration and DNA origami area was established. ${ }^{56}$ Also, similar conclusions have been drawn from small-angle X-ray scattering experiments by Qiu et al. ${ }^{32,57,58}$

To quantify the screening of the negative charges on the DNA backbone phosphates, we subsequently counted the number of ions condensing on the origami. In Figure 1i, the fraction of DNA charge compensated by ions within $5 \AA$ (the characteristic distance to find bound ions in, see Figure S4, and of the order of the Debye length in physiological solution ${ }^{47}$ ) of DNA atoms in the Sodium, Mixed, and Magnesium simulations is shown as a function of time. In all cases, this fraction remains constant over time, with higher values in systems containing more $\mathrm{Mg}^{2+}$. As the positive charges of $\mathrm{K}_{10}$ and $\mathrm{Spm}^{4+}$ are centered on their nitrogen atoms, the fraction of DNA charge compensated by these nitrogens within $5 \AA$ of DNA atoms for the PLL-10 and Spermine simulations is plotted in Figure $1 \mathrm{i}$ as well. $\mathrm{Spm}^{4+}$ and $\mathrm{K}_{10}$ both show fractions higher than in the other simulations, which can be attributed to the polyvalency effects of these charged molecules. Bloomfield ${ }^{28}$ has shown that condensation of DNA occurs when more than $90 \%$ of its charge is neutralized. The observed increase in aspect ratio in the Spermine simulation is therefore explained by the high number of $\mathrm{Spm}^{4+}$ ions, approximately $90 \%$, localized near the origami. The fraction of $\mathrm{K}_{10}$ nitrogens near the origami rises slowly compared to the other ions but steadily reaches a level close to the fraction of $\mathrm{Spm}^{4+}$ ions. Together, the RMSD, aspect ratio, and ion condensation analyses show that $\mathrm{Na}^{+}$and $\mathrm{Mg}^{2+}$ cause larger global conformational changes than do $\mathrm{Spm}^{4+}$ and $\mathrm{K}_{10}$ and that the change of shape of the origami itself is significantly different in the Spermine simulation. $\mathrm{Na}^{+}$ has a lower affinity for the DNA origami than $\mathrm{Mg}^{2+}$, followed by $\mathrm{K}_{10}$ and $\mathrm{Spm}^{4+}$, which cause gradually less repulsion between parallel DNA helices.

Structure and Stability. Having established the effect of the different ions on global conformational changes, we next examined the fluctuations of the structures in more detail to obtain insight in local deformations and DNA origami stability. To that end, we calculated the root-mean-square fluctuation (RMSF) for the center of mass for each nucleotide. Figure $2 \mathrm{a}$ shows a representation of these RMSF values for the Magnesium simulation, containing the typical ionic environment in in vitro experiments, mapped onto the time-averaged structure. The largest fluctuations in space occur at the edges of the origami, while the center remains rather rigid. The increased fluctuations at the edges of the DNA origami are caused by the lack of crossovers in the edge regions, which comprise a relatively large part of the origami design used in our simulations. The full-size origami typically employed experimentally would have a relatively much larger interconnected part constrained by crossovers. The fluctuations at the edges are also difficult to compare with experiments, as typical DNA origami experiments exclude the edge staples. This is because the ends of the origami helices, where one strand terminates and its complementary forms a U-turn, effectively form blunt ends, causing aggregation between separate origamis. ${ }^{1}$ These effects could be diminished by constructing an infinite DNA origami system that binds to itself over the periodic boundaries, ${ }^{56}$ though imposing such strict constraints upon the origami could introduce artifacts in its own. A qualitatively similar picture as observed for $\mathrm{Mg}^{2+}$ is displayed for the other ion types (see Figure S5). However, the magnitude of fluctuations clearly differs between simulations and shows a trend comparable to the final RMSD values where the fluctuations in the Sodium simulation are highest and that in the PLL-10 simulation lowest.

As destabilization of DNA is typically associated with dehybridization of base pairs, we also analyzed whether the base pairs in the initial structure remain intact during the simulations. To this end, we quantified the fractions of time base pairs are broken. A base pair is defined to be intact, that is, not broken, if it has formed two or three hydrogen bonds for $\mathrm{A}-\mathrm{T}$ and $\mathrm{G}-\mathrm{C}$ pairs, respectively, where we count a hydrogen bond if the hydrogen-acceptor distance is within $2.9 \AA$ and the donor-hydrogen-acceptor angle is at least $120^{\circ}$. Analysis of the Magnesium simulation (Figure $2 \mathrm{~b}$ ) shows that primarily base pairs near crossover regions and at the edges of the origami are broken. Base pairs in blunt ends at the edges are susceptible to fraying, while bases near crossovers in the center of the origami experience a larger stress from the structure that forces it in a certain conformation, which is not optimal for the formation of DNA base pairs. No clear difference between different ion concentrations or ion types is observed (see Figure S6), which indicates that breaking of base pairs near crossovers is not related to ion types but inherent to the DNA origami. Further research with other DNA origami designs could explain whether this is a design-specific effect or if this is inherent to all DNA origami constructs.

While the RMSF and base pair analyses reveal that the extent of internal instabilities in the origami structures is similar across simulations, small local deformations could still drive structural deformations at the global level. To quantify these local deformations, we studied bending of DNA helices, as well as the angles between two helices in crossover regions for different ion types. First, the angle between the two vectors connecting the centers of mass of three subsequent base pairs is assessed (Figure 2c). In Figure $2 \mathrm{~d}$ and e, this angle $\psi$ averaged over time is shown as a function of the base index $(i)$ within the two middle helices of the DNA origami for the Sodium simulation as well as a snapshot of the corresponding helices. The angles at crossover locations are clearly larger than those in regions without crossovers, which corroborate recent coarse grained-simulations of a larger DNA origami. ${ }^{59}$ Interestingly, in helix 5 (Figure 2e), an additional peak is observed at base index 38, that is, eight bases away from the nearest crossover. Inspection of the DNA sequence shows that at this position one staple strand ends and another one starts, effectively introducing a nick in the helix. That in helix 4 no 
a

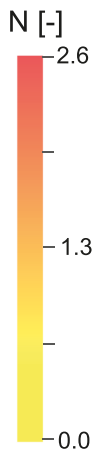

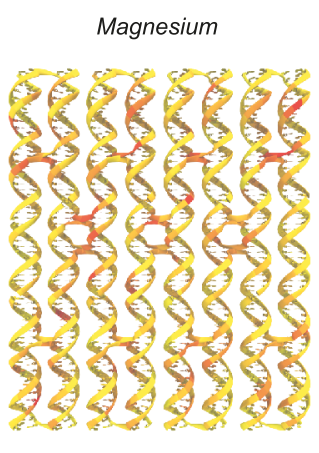

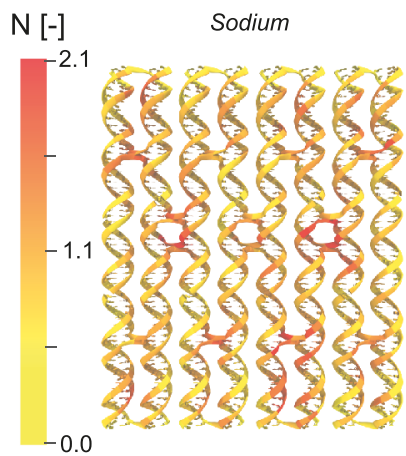

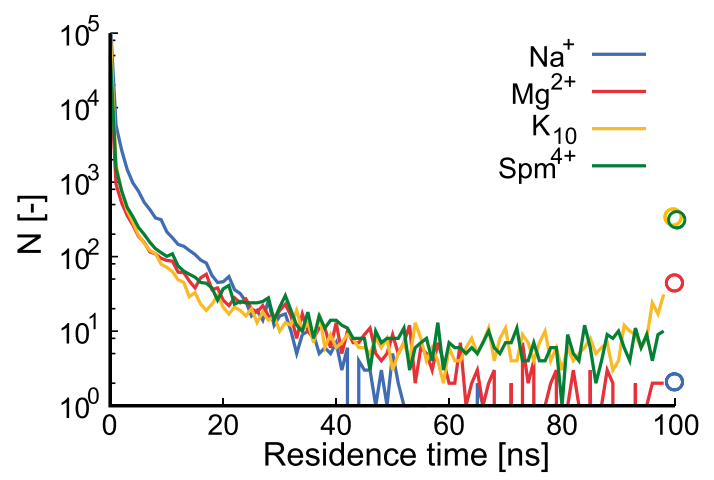

C

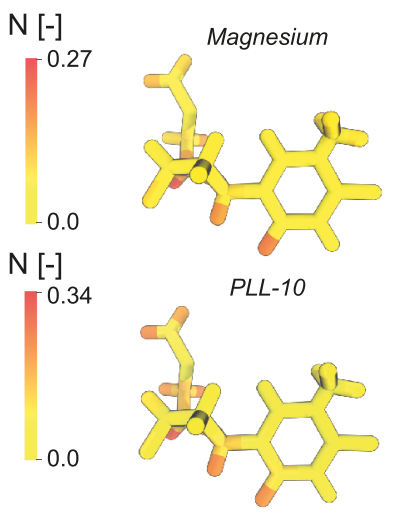

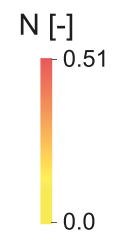

$\mathrm{N}[-]$
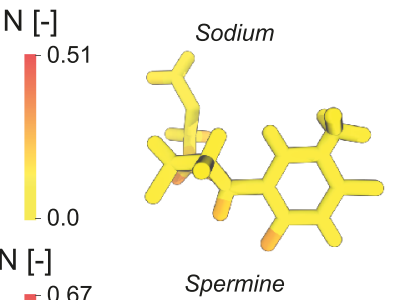

0.67
0.0 d

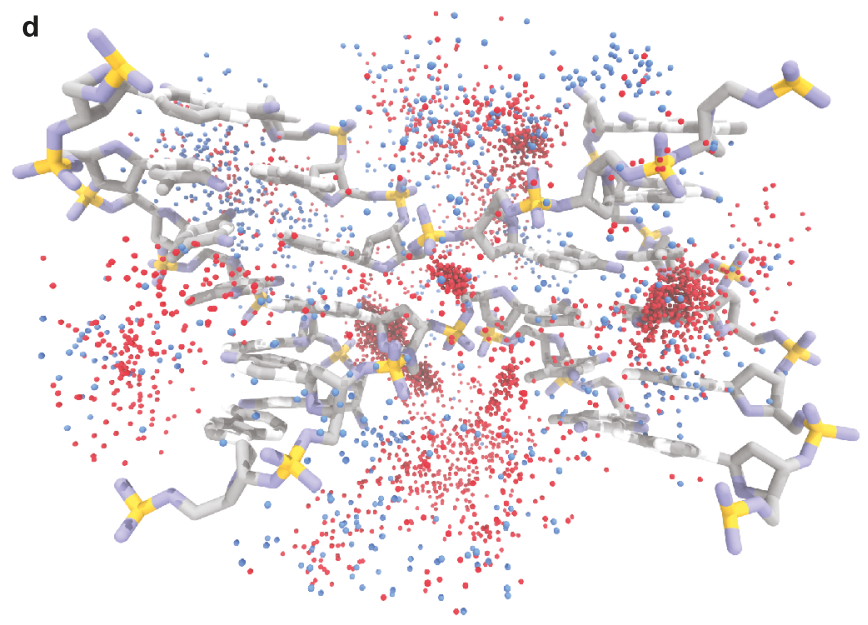

Figure 3. Analysis of binding of ions to the DNA origami. (a) Number of ions within $5 \AA$ of each nucleotide averaged over time in the Magnesium and the Sodium simulation, respectively, mapped onto the initial origami structure. (b) Residence times of ions within $12 \AA$ of the DNA origami. Circles at $100 \mathrm{~ns}$ indicate ions that are near the DNA during the full simulation time. (c) Number of ions within $5 \AA$ of each atom in thymine, averaged over time and all thymine nucleotides. (d) Superposition of 100 frames of a crossover region in the Mixed simulation showing $\mathrm{Mg}^{2+}$ (red) binding at more defined regions and $\mathrm{Na}^{+}$(blue) binding further away at less defined positions.

clear kink is observed at a similar nick present at base index 22, may be attributed to the presence of a crossover only three bases away. These $\psi$-profiles repeat across the DNA origami (see Figure S7), matching the inherent periodicity of the design. Since crossover regions are the main difference between DNA origami nanostructures and previous work on the condensation of parallel DNA bundles, we aimed to characterize these regions in more detail. To this end, we defined two more angles, $\theta$ and $\phi$, described by the four vectors between the centers of mass of base pairs adjacent to the crossovers and those three base pairs away (Figure 2f). Here, $\theta$ is defined as the angle between parallel vectors across helices, while $\phi$ is defined as the angle between antiparallel vectors within a helix. Probability density functions of the angles for all five simulations, averaged over time and all crossovers, are shown in Figure $2 \mathrm{~g}$ and $\mathrm{h}$. For $\theta$, a trend can be observed in the Sodium, Mixed, and Magnesium simulations where a decreasing amount of $\mathrm{Mg}^{2+}$ results in wider angles. This is in line with the difference in aspect ratios in Figure 1h, where we observe that lower $\mathrm{Mg}^{2+}$ concentrations lead to stronger repulsion between DNA helices, forcing crossovers in an "X"-conformation. The PLL-10 and, even more strongly, the Spermine simulations display the smallest $\theta$ angles, showing that the crossovers retain an " $\mathrm{H}$ "-conformation. In contrast, no similar clear trend with $\mathrm{Mg}^{2+}$ concentration can be distinguished in the probability distributions of $\phi$. Visual inspection reveals that the lack of correlation between $\theta$ and $\phi$ stems from the crossovers moving out of plane, especially in the Sodium and Mixed simulations. However, in the case of the Magnesium simulation, more $\phi$ angles close to $180^{\circ}$ can be observed than in the other simulations, showing that $\mathrm{Mg}^{2+}$ ions allow the DNA helices to run relatively straight and that they are less influenced by the presence of crossover junctions. Collectively, these results show that different ions do not affect the structural integrity of the double helices at the time scale of our simulations but influence the global origami structure via the conformations of crossovers and repulsion of parallel helices.

Binding of lons. The above results revealed the effect of the distinct ions on conformational changes in the DNA origami structure. To explain the observed structural differences, we subsequently studied the preferential binding mechanisms of the distinct ions by zooming in onto the interactions of the ions with individual nucleotides and atoms in the DNA origami. First, we quantified preferential binding positions on the DNA origami rectangle by time-averaging the number of ions within $5 \AA$ of every nucleotide. The results for the Magnesium and the Sodium simulations are shown in Figure $3 \mathrm{a}$ and those of the other simulations in Figures S8 and S9. In all cases, nucleotides at the edge of the origami are observed to bind fewer ions compared to nucleotides in the center of the rectangle, which can be explained by the lower density of 


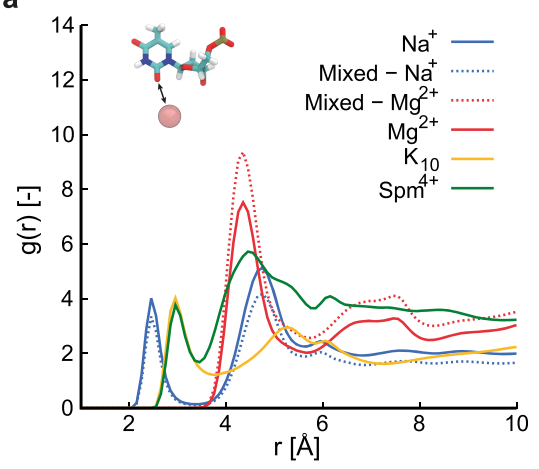

d

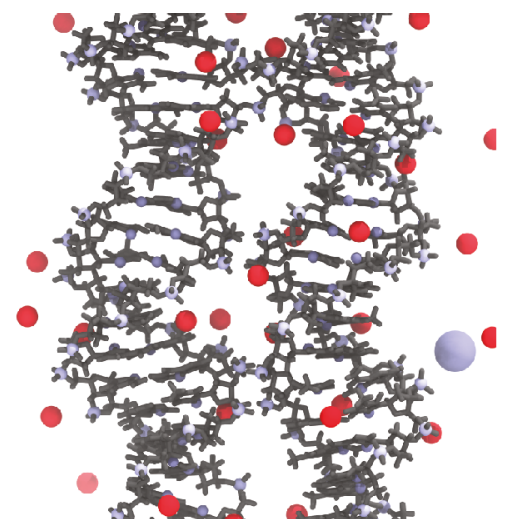

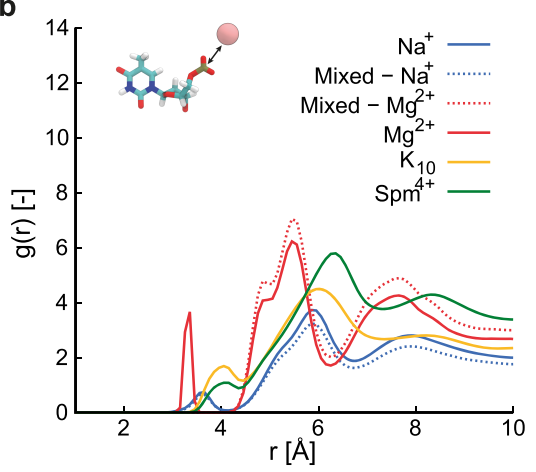

e

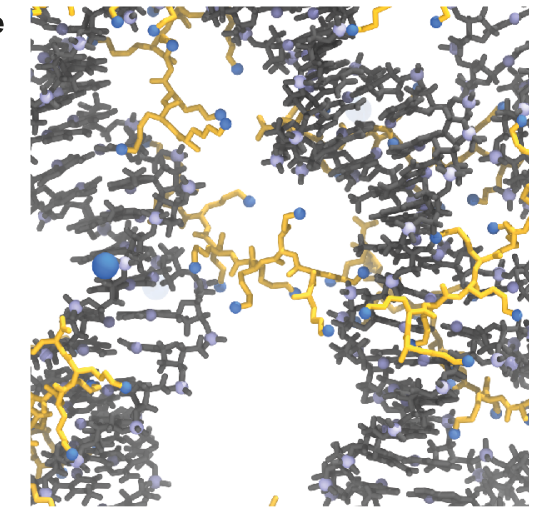

C
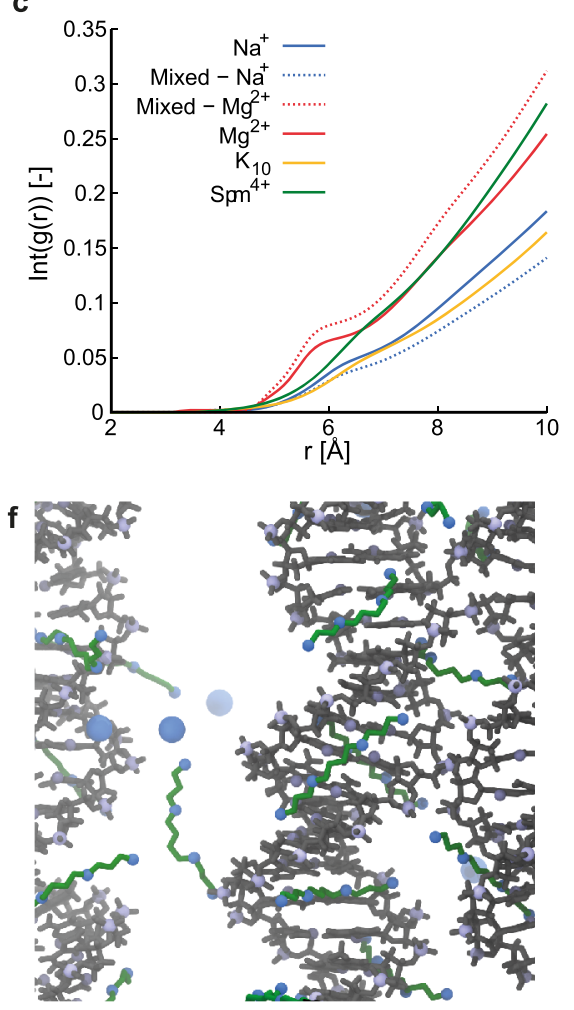

Figure 4. Illustration of typical binding of ions to DNA origami. (a) Radial distribution function between ions and atoms located in the minor groove of the DNA origami helix. (b) Radial distribution function between ions and phospohorus atoms in the DNA backbone. (c) Integral of the radial distribution function between ions and all phosphorus atoms in the nucleotides forming crossover junctions. (d-f) Zoomed in simulation snapshots illustrating typical binding of $\mathrm{Mg}^{2+}, \mathrm{K}_{10}$, and $\mathrm{Spm}^{4+}$, respectively, with DNA origami shown in gray, $\mathrm{Mg}^{2+}$ in red, $\mathrm{K}_{10}$ in yellow, $\mathrm{Spm}^{4+}$ in green, and nitrogen in blue.

negatively charged phosphates at the edges compared to the center, especially at crossover regions. Comparison of the Magnesium and Sodium simulations reveals a more homogeneous distribution of ions over the origami in the latter. This indicates that $\mathrm{Na}^{+}$either has a lower preference for particular locations in the origami, or that $\mathrm{Na}^{+}$ions regularly unbind and bind at other positions, or even diffuse over the surface without forming specific interactions. $\mathrm{Spm}^{4+}$ and $\mathrm{Mg}^{2+}$ show the highest number of charges near crossovers compared to the other ion types. The PLL-10 and Spermine simulations show a slight increase of ions near crossovers, but overall the ions are more randomly distributed over the structure compared to the Magnesium simulation.

Apart from differences in distribution of ions across the DNA origami nanostructure, we also observed differences in the lengths of the time intervals for which ions reside within 12 $\AA$ of the origami. These residence times (Figure $3 b$ ) are observed to be much shorter for $\mathrm{Na}^{+}$compared to other ions. Only two $\mathrm{Na}^{+}$ions remain within $12 \AA$ of the DNA backbone over a time interval of $60 \mathrm{~ns}$ and longer. In contrast, $43 \mathrm{Mg}^{2+}$ ions show residence times of at least the duration of the entire simulation. For $\mathrm{K}_{10}$ and $\mathrm{Spm}^{4+}$, the majority of charge centers remain near the DNA for the duration of the simulation, consistent with the earlier global ion analysis, which showed that almost all ions are localized near the origami at any given moment in the simulation.

$\mathrm{Na}^{+}$and $\mathrm{Mg}^{2+}$ are known to bind sequence-dependently to the major and minor groove with a preference of $\mathrm{Mg}^{2+}$ for guanine and adenine in both major and minor grooves. ${ }^{60} \mathrm{Na}^{+}$ has also been shown to bind preferentially to thymine in the minor groove but to guanine and adenine in the major groove. $^{61}$ Though the origami structure in our simulations differs significantly from the dodecamers used in these studies and does not contain long AT or CG domains, we next averaged the amount of ions within $5 \AA$ of a nucleotide over all nucleotides of the same type to analyze if base type dependent binding of ions plays an important role in this DNA origami. For each nucleotide type, we determined the average amount of ions or nitrogens near a nucleotide (Table S2). These data reveal that in all simulations, adenine and guanine are more subject to ion binding, which can be explained by the higher number of atoms in these bases. However, no further significant preferences for specific nucleotide types were observed.

To investigate possible base type dependent binding of the distinct ions in more detail, we also quantified the average amount of ions near each nucleotide type at the atomistic level. The results for thymine bases in Figure $3 \mathrm{c}$ show that $\mathrm{Mg}^{2+}$ is often localized near the carbonyl oxygen in the minor grooveside of the nucleotide and near backbone atoms, while it is found very infrequently near other atoms in the thymine base ring. Also for other nucleotides (see Figure S10), $\mathrm{Mg}^{2+}$ often appears to bind near minor-groove atoms, mainly in adenine and guanine, and near backbone phosphates. $\mathrm{Na}^{+}$is also found frequently near minor-groove atoms, while little binding is observed near the backbone or the major groove for all nucleotides. For $\mathrm{K}_{10}$, penetration of amines into the grooves of the DNA is relatively uncommon and while some minor groove binding is observed, $\mathrm{K}_{10}$ mainly binds to the DNA backbone. This is in agreement with a recent study that 

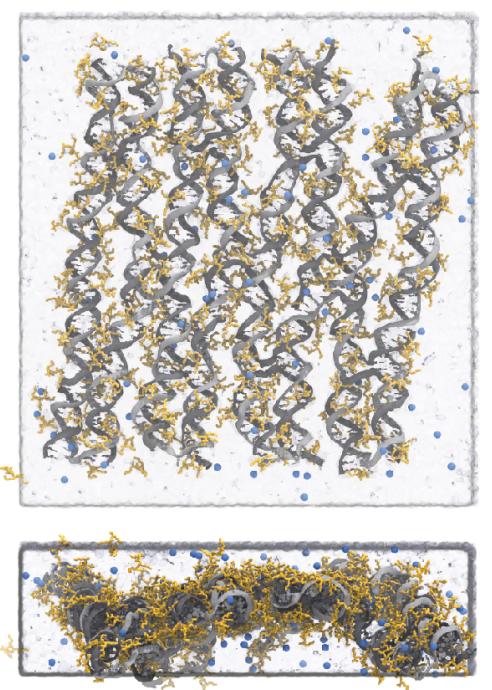

b

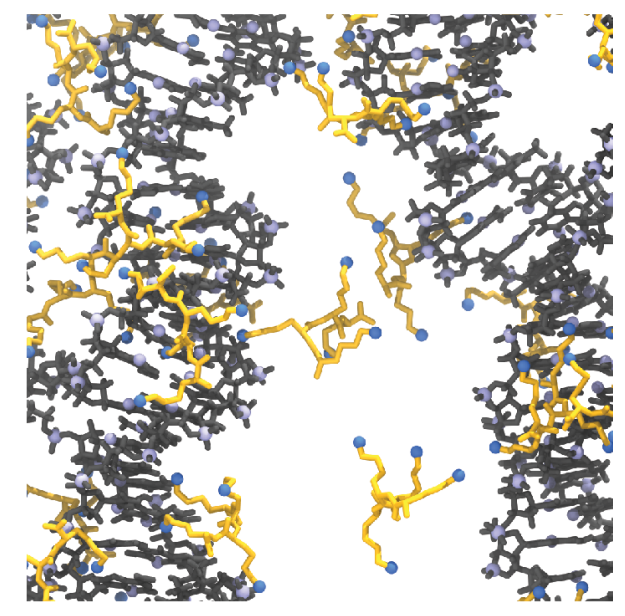

C

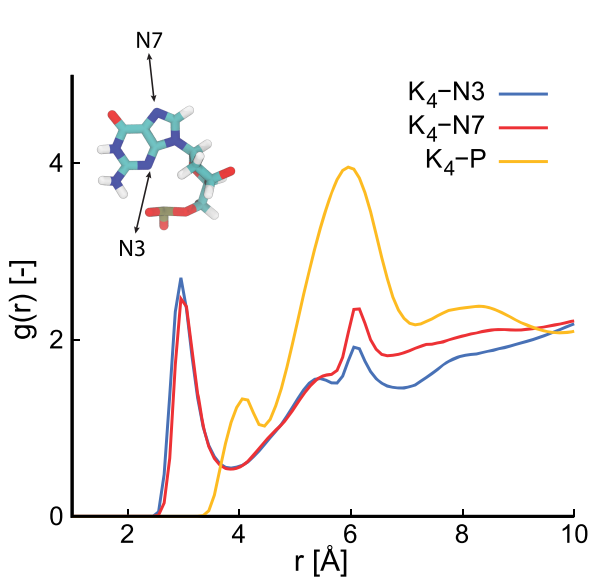

Figure 5. PLL-4 simulation. (a) Snapshot of the final configuration in two orientations, with the DNA origami shown in gray, water in light blue and $\mathrm{Na}^{+}$and $\mathrm{K}_{4}$ in blue and yellow, respectively. (b) Zoomed in simulation snapshot illustrating typical binding of $\mathrm{K}_{4}$, with DNA origami shown in gray, $\mathrm{K}_{4}$ in yellow, and nitrogen in blue. (c) Radial distribution function between nitrogens in $\mathrm{K}_{4}$ and minor groove atoms, major groove atoms, and phosphorus atoms in the DNA backbone, respectively. The inset indicates the minor (N3) and major (N7) groove atoms used in the case of guanine.

showed that $\mathrm{K}_{6}$ does not bind strongly to the major and minor groove, especially in AT-rich regions. ${ }^{62}$ In the Spermine simulation, $\mathrm{Spm}^{4+}$ shows only little binding to phosphate groups in the DNA backbone, and mainly binds to major groove atoms in guanine. This sequence-dependency of $\mathrm{Spm}^{4+}$ binding has also been observed by Yoo et al., who showed that the methyl group in thymine prevents $\mathrm{Spm}^{4+}$ binding to the major groove in AT-rich regions, while it does bind in the major groove of GC-rich regions. ${ }^{36}$ For thymine and adenine, we observe that $\mathrm{Spm}^{4+}$ binds in the minor groove instead and through visual inspection we observe them in the regions in between helices as well. This has previously been shown to cause a stronger attraction between helices and has been referred to as the "bridging" of Spm ${ }^{4+}$ molecules between DNA duplexes. $36,53,63$

To visualize the difference between $\mathrm{Mg}^{2+}$ and $\mathrm{Na}^{+}$binding, we aligned one crossover junction over 100 frames in the Mixed simulation. In Figure $3 \mathrm{~d}$, the crossover and the surrounding ions over all 100 frames are shown. We observe clusters of $\mathrm{Mg}^{2+}$ at specific locations near the crossover in line with our previous analysis. These are mainly $\mathrm{Mg}^{2+}$-ions with long residence times, while $\mathrm{Na}^{+}$-ions are primarily scattered at larger distances from the origami.

We further quantified the preferential binding positions of ions by determining the radial distribution functions (rdf) between ions and DNA atoms in the minor groove, and between ions and phosphorus atoms in the DNA backbone. For the minor groove-ion-rdf we considered the carboxyl oxygen on thymine and cytosine bases and the hydrogen of the secondary amine in guanine and adenine bases (Figure 4a). The highest peak of $\mathrm{Mg}^{2+}$ is located at the same distance as the highest $\mathrm{Spm}^{4+}$ peak at $4 \AA$, while the peak of $\mathrm{Na}^{+}$is at a larger distance of $5 \AA$. In contrast, the $\mathrm{rdf}$ for $\mathrm{K}_{10}$ fluctuates around a value of 2 with less defined peaks, indicating that $\mathrm{K}_{10}$ does not bind close to minor groove atoms, corroborating the results in Figures $3 c$ and S10. In the phosphorus-ion-rdf (Figure $4 b$ ), the main peak for $\mathrm{Spm}^{4+}$ at $6.5 \AA$ indicates binding to the grooves, with a smaller one at $4 \AA$ indicating limited direct binding to phosphates. $\mathrm{Na}^{+}$and $\mathrm{K}_{10}$ display a peak at a similar distance of $6 \AA$, while $\mathrm{Mg}^{2+}$ is typically closer to phosphorus at $5.5 \AA$, which can be an effect of both a higher charge and a smaller ionic radius.

As analysis of preferential binding regions on the origami suggested that some ions bind close to crossover regions more frequently than others, we also determined the rdfs between ions and phosphorus atoms of the four nucleotides forming the crossovers. The integrals of these rdfs (Figure 4c) clearly show that mainly $\mathrm{Mg}^{2+}$ binds close to crossover phosphates. Also, for $\mathrm{Spm}^{4+}$ approximately $50 \%$ more charge is located within $10 \AA$ of the crossover phosphates compared to $\mathrm{K}_{10}$ and $\mathrm{Na}^{+} . \mathrm{K}_{10}$ and $\mathrm{Na}^{+}$bind at similar distances further away from the crossover phosphates. This enhanced charge compensation of crossover phosphates compared to other ions explains for the improved ability of $\mathrm{Mg}^{2+}$ and $\mathrm{Spm}^{4+}$ to stabilize crossovers and retain the parallel conformation of adjacent helices.

Together, these results reveal that $\mathrm{Mg}^{2+}$ binds closely to the DNA origami and is more likely to bind specific locations near crossovers, which has been shown to rigidify crossovers, ${ }^{64,65}$ whereas $\mathrm{Na}^{+}$binds at a larger distance from the origami and rapidly exchanges with the bulk solvent. $\mathrm{Spm}^{4+}$ binds closely to the DNA origami grooves, aligning with the backbone phosphates and shows, together with $\mathrm{Mg}^{2+}$ ions, the highest charge compensation near crossovers, while $K_{10}$ is able to stabilize DNA origami without binding deeply in the grooves. Snapshots illustrating typical binding of $\mathrm{Mg}^{2+}, \mathrm{K}_{10}$, and $\mathrm{Spm}^{4+}$ are shown in Figures $4 \mathrm{~d}, \mathrm{e}$, and $\mathrm{f}$, respectively. In these snapshots, $\mathrm{Mg}^{2+}$ is seen bound in the DNA minor groove, as well as directly near phosphate groups around a crossover, and $\mathrm{Spm}^{4+}$ bound in, and aligned with, the minor groove. $\mathrm{Spm}^{4+}$, as mentioned before, is also seen in between neighboring DNA helices, suggesting a mechanism similar to the "bridging" model of DNA helix attraction. ${ }^{36,53,54,63} \mathrm{~K}_{10}$ reveals a mechanism where part of the peptide binds to one helix and another part to a neighboring helix, effectively spanning over 
DNA origami helices. Not only does this mechanism explain for the high capability of $\mathrm{K}_{10}$ to stabilize DNA origami but also for the experimentally observed aggregation of DNA origamis in the presence of polylysines with more than 10 units, ${ }^{25}$ namely by simultaneously binding to helices in different origamis.

DNA Origami Stabilization by $\mathrm{K}_{\mathbf{4}}$. The observation that $\mathrm{K}_{10}$ stabilizes DNA origami by simultaneously binding adjacent DNA helices, while tetravalent $\mathrm{Spm}^{4+}$ does so by binding closely in the DNA grooves and in between helices, reducing strain on crossovers, triggered us to perform an additional simulation with shorter oligolysines as counterions. For this simulation, denoted as the PLL-4 simulation, we chose $\mathrm{K}_{n}$ molecules with $n=4$ to maintain the same charge per molecule as $\mathrm{Spm}^{4+}$ while retaining the molecular structure of oligolysine. Visual inspection of the final configuration (Figure 5a) shows a larger deviation from the initial structure compared to both the PLL-10 and Spermine simulations. The edges of the origami move outward, indicating that $\mathrm{K}_{4}$ is less able to reduce the repulsive forces between backbone phosphates. This is confirmed by the RMSD values for the DNA backbone (Figure S11), which are higher than those for the PLL-10 and Spermine simulations. Observing the crossover angles $\theta$ and $\phi$, we find that both have an increased probability toward angles of 90 deg compared to the Spermine and PLL-10 simulations (Figure S12), indicating that $\mathrm{K}_{4}$ does not stabilize crossovers efficiently. Radial distribution functions reveal that $\mathrm{K}_{4}$ side chains bind closely to both the N3 and N7 nitrogens in the minor and major grooves, respectively (Figure 5c). On the level of individual atoms (as in Figure 3c), we observe similar preferential binding as for $\mathrm{K}_{10}$, but with an enhanced preference for the major groove of guanine (see Figure S10). This is explained by the presence of a carbonyl group at the major groove side of guanine, which attracts $K_{4}$ side chains more strongly to the major groove compared to adenine. The larger size of $\mathrm{K}_{10}$ as opposed to $\mathrm{K}_{4}$ causes side chains to be more constrained, reducing their ability to reach into the guanine major groove to form more favorable interactions. Typical binding of $\mathrm{K}_{4}$ to DNA origami is shown in Figure $5 \mathrm{~b}$ and shows that the methyl group in the major groove side of thymine prevents binding to AT-rich regions. ${ }^{36}$ Also, $\mathrm{K}_{4}$ amine side chains reach toward the major groove side of guanine.

To confirm if the typical bridging behavior observed for $\mathrm{K}_{10}$ occurs to a lesser degree for $\mathrm{K}_{4}$, we finally quantified the fractions of molecules that bind to more than one helix at the same time, where binding is again defined as one of the $\mathrm{N}$ atoms in the counterion being within $5 \AA$ of any DNA atom in that helix. Averaged over time, $62 \%$ of the $\mathrm{K}_{10}$ molecules bind to two helices. In contrast, only $24 \%$ of the $\mathrm{K}_{4}$ molecules bind to more than one helix at the time, while for $\mathrm{Spm}^{4+}$ this percentage is $23 \%$. Despite its identical structure to $\mathrm{K}_{10}$ and its equal valency to $\mathrm{Spm}^{4+}, \mathrm{K}_{4}$ can thus neither stabilize the DNA origami by aligning in the DNA grooves like $\mathrm{Spm}^{4+}$ nor by spanning over helices like $\mathrm{K}_{10}$.

\section{CONCLUSIONS}

We have used atomistic MD simulations to analyze the effect of various ion types on a 512 bp DNA origami rectangle and the structure of its crossovers. The high spatial-temporal resolution of these simulations provides a molecular picture of DNA origami stabilization that cannot be directly observed experimentally. $\mathrm{Na}^{+}$has been shown to bind only weakly to the DNA origami and to rapidly exchange with the solvent, resulting in a too weak screening of the negative charges on the DNA backbone to prevent repulsion of parallel helices and destabilization of crossovers. In contrast, $\mathrm{Mg}^{2+}$ does not only bind to the DNA origami to a higher extent, it also binds more closely and resides at specific locations for extended periods of time, also at crossovers. As a result, it stabilizes the origami by screening the negative charges on the backbone more efficiently and maintaining crossovers in an " $\mathrm{H}$ " conformation. $\mathrm{Spm}^{4+}$ molecules condense even stronger on the DNA and bind especially closely in the minor groove near thymine and adenine, and in the major groove near guanine with long residence times as well as in between helices. Being able to retain the parallel orientation of DNA helices more than the other counterions, $\mathrm{Spm}^{4+}$ has an increased capability to stabilize crossovers in " $\mathrm{H}$ " conformation. This correlates with the prevention of repulsion between DNA helices, resulting in condensation of helices and therefore a higher aspect ratio of the origami compared to the other simulations. $\mathrm{K}_{10}$ molecules show the longest residence times near the origami and bind directly to the backbone rather than penetrating the DNA grooves and keep helices together by simultaneous binding of adjacent helices with its flexible side chains, in this way spanning parallel helices. We thus reveal two main mechanisms of DNA origami stabilization: (i) binding of high charge density ions like $\mathrm{Mg}^{2+}$ and $\mathrm{Spm}^{4+}$ stabilizes crossovers and reduces repulsion of parallel helices and (ii) binding of long flexible ions like $\mathrm{K}_{10}$ that interconnect adjacent helices by simultaneous binding of different parts of the ion. A simulation with $\mathrm{K}_{4}$, that is, a counterion with the same valency as $\mathrm{Spm}^{4+}$ and the same molecular structure as $\mathrm{K}_{10}$ but that is too short to span multiple DNA helices and does not have the high charge density of $\mathrm{Spm}^{4+}$, showed that $\mathrm{K}_{4}$ is indeed a weaker stabilizer than both $\mathrm{K}_{10}$ and $\mathrm{Spm}^{4+}$, though still stronger than $\mathrm{Na}^{+}$. Altogether, this shows that ions can stabilize DNA origami via distinct mechanisms and that for stabilization either a higher number of weakly binding amines like in $\mathrm{K}_{10}$ or a smaller but stronger binding molecule like $\mathrm{Spm}^{4+}$ or $\mathrm{Mg}^{2+}$ is required.

Combining both strategies, that is, preventing helix repulsion and simultaneously binding adjacent helices, by using mixtures of ion types could lead to enhanced stabilization of DNA nanostructures. For instance, while $\mathrm{K}_{10}, \mathrm{Spm}^{4+}$, and $\mathrm{Mg}^{2+}$ have been shown to be efficient stabilizers for the DNA origami nanostructure used in our simulations, $\mathrm{K}_{10}$ may not be able to stabilize larger three-dimensional designs as it is too large to penetrate the structure and neutralize the inner regions of the nanostructure. In this case, optimal stabilization might be obtained by a combination of smaller ions, for example, $\mathrm{Mg}^{2+}$ or spermine with a $\mathrm{K}_{10}$ coating on the outside of the DNA nanostructure. Another interesting avenue would be to consider another ion type that integrates both stabilization mechanisms. A promising example in this respect may be a second-generation polypropyleneimine dendrimer, a molecule with structural similarity to $\mathrm{Spm}^{4+}$ that approaches the length of $\mathrm{K}_{10}$ in its fully extended conformation. In addition, given the apparent importance of high charge density of ions to stabilize crossovers, a third interesting avenue would be the investigation of other compact multivalent ions that have been studied in the context of DNA, for example, cobalt hexammine. ${ }^{31,53}$ Though further computational and experimental work is required to determine if such mixtures of ions, dendrimers or other high charge density cations are indeed able to more efficiently stabilize DNA origami, the simulations presented here already shed light on the binding mechanisms 
of $\mathrm{Mg}^{2+}, \mathrm{Na}^{+}, \mathrm{K}_{10}, \mathrm{Spm}^{4+}$, and $\mathrm{K}_{4}$ to DNA origami at an atomistic level and showed their modes of stabilization. Understanding of these mechanisms of stabilization is an important prerequisite to open up the biomedical applicability of these versatile nanostructures.

\section{METHODS}

Simulation Setup. The origami rectangle was designed using caDNAno $^{66}$ and subsequently converted into an atomistic representation using a tool developed by Aksimentiev et al. ${ }^{38,67}$ This atomistic representation of the DNA origami rectangle was dissolved in aqueous solutions containing different ions: $\mathrm{Na}^{+}$, a mix of $\mathrm{Na}^{+}$and $\mathrm{Mg}^{2+}, \mathrm{Mg}^{2+}$, $\mathrm{K}_{10}, \mathrm{Spm}^{4+}$, and $\mathrm{K}_{4}$, termed the Sodium, Mixed, Magnesium, PLL-10, Spermine, and PLL-4 simulation, respectively. For the Magnesium, Mixed, and Sodium simulations, the DNA origami structure was first solvated in TIP3P water $^{68}$ using VMD's ${ }^{69}$ solvate tool in a simulation box with dimensions $250 \times 70 \times 270 \AA^{3}$. Subsequently, using the ionize tool in $\mathrm{VMD},{ }^{69}$ random water molecules were replaced with $\mathrm{Mg}^{2+}$ or $\mathrm{Na}^{+}$to neutralize the system and with additional ions to reach excess ion concentrations of $10 \mathrm{mM} \mathrm{MgCl}_{2}, 5 \mathrm{mM} \mathrm{MgCl}_{2}$, and $10 \mathrm{mM} \mathrm{NaCl}$ or $20 \mathrm{mM} \mathrm{NaCl}$ in the Magnesium, Mixed, or Sodium simulation, respectively. For the PLL-10, Spermine, and PLL-4 simulations, first $100 \mathrm{~K}_{10}, 250 \mathrm{Spm}^{4+}$, and $250 \mathrm{~K}_{4}$ molecules, respectively, were added to the system using a custom Python script to reach a nitrogen:phosphorus (N:P)-ratio of approximately 1:1. After solvation with TIP3P water in a simulation box with dimensions $250 \times 70 \times 270 \AA^{3}$, random water molecules were replaced with $\mathrm{Na}^{+}$ and $\mathrm{Cl}^{-}$to reach the same amount of added positive and negative charges in the system as in the other simulations (see Table S1 for details).

Simulation Protocol. The simulation protocol is largely based on the protocol used by Yoo and Aksimentiev. ${ }^{38}$ All simulations were performed using $\mathrm{NAMD}^{70}$ with periodic boundary conditions, the CHARMM36 force field optimized for $\mathrm{DNA}^{71}$ with improved parameters for ions ${ }^{72}$ and polyamines, ${ }^{73} 1-4$ nonbonded exclusions, a 10-12 $\AA$ switching scheme for nonbonded interactions, and electrostatic interactions treated using a particle-mesh Ewald scheme with a grid spacing of $1 \AA$. In the molecular dynamics simulations, temperature was controlled using a Langevin thermostat, ${ }^{70}$ and pressure was controlled at one bar using a Nosé-Hoover barostat. ${ }^{74}$

First, we perform an equilibration protocol. The first step of this protocol comprised $10^{4}$ steps of energy minimization while keeping the positions of all DNA origami backbone atoms fixed. To ascertain that in the simulations containing $\mathrm{Mg}^{2+}$, magnesium hexahydrates were formed, we restrained the six water oxygen atoms closest to each $\mathrm{Mg}^{2+}$ ion using harmonic restraints with an equilibrium distance of $1.94 \AA$ and a force constant of $1 \mathrm{kcal} / \mathrm{mol} / \AA^{2}$, and performed an additional short minimization to let the system adjust to these restraints. The second step of the equilibration protocol comprised a short NVT molecular dynamics run in which the temperature is increased in a stepwise fashion from 0 to $295 \mathrm{~K}$. To give the ions a more random orientation with respect to the starting structure in the PLL-10, Spermine, and PLL-4 simulations, an NPT run of $0.5-1.5 \mathrm{~ns}$ was performed where for each polyamine one atom at its center was kept fixed. The next step of the equilibration protocol comprised an NPT run of 3-4 ns where all ions could freely diffuse toward the origami of which the backbone was still restrained. In these runs a high piston period of $1000 \mathrm{fs}$ was used to prevent the simulation from crashing. Then, for all simulations we released the DNA origami and the hexahydrate restraints and performed another short minimization and NVT run. Finally, we started the 100 ns production run in an NPT ensemble at a temperature of $298 \mathrm{~K}$ and a pressure of one bar with a piston period of $200 \mathrm{fs}$. Simulations were performed partly on our local computing cluster, but mainly on Cartesius, the Dutch national supercomputer.

Analysis. All analyses were performed using in-house developed Python scripts, which made use of the MDAnalysis module to read in trajectory files and perform atom selections. ${ }^{75}$ Radial distribution functions were computed using VMD's built-in analysis tool. ${ }^{76}$

\section{ASSOCIATED CONTENT}

\section{Supporting Information}

The Supporting Information is available free of charge on the ACS Publications website at DOI: 10.1021/acsnano.9b05650.

Figures of molecular structures of $\mathrm{K}_{n}$ and $\mathrm{Spm}^{4+}$, representation of DNA origami considered, additional data on RMSD, RMSF, broken base pairs, internal angles, and number of ions near origami, tables containing number of ions near distinct nucleotide types and number of molecules (PDF)

\section{AUTHOR INFORMATION}

\section{Corresponding Authors}

*E-mail: t.f.a.d.greef@tue.nl.

*E-mail: a.j.markvoort@tue.nl.

ORCID

Tom F. A. de Greef: 0000-0002-9338-284X

Albert J. Markvoort: 0000-0001-6025-9557

\section{Notes}

The authors declare no competing financial interest.

\section{ACKNOWLEDGMENTS}

The authors would like to thank B. Rosier for helpful discussions about DNA origami and A. van Dorp and T. van Sonsbeek for their contributions to the analysis of the simulations. This work was supported by the European Research Council, ERC (Project No. 677313 BioCircuit), an NWO-VIDI grant from The Netherlands Organization for Scientific Research (NWO, 723.016.003), and funding from the Ministry of Education, Culture, and Science (Gravity programs 024.001.035 and 024.003.013). Simulations were performed on Cartesius, the Dutch national supercomputer, managed bij SURFsara, funded by NWO program Computing Time on National Computer Facilities (Project No. 15862).

\section{REFERENCES}

(1) Rothemund, P. W. K. Folding DNA to Create Nanoscale Shapes and Patterns. Nature 2006, 440, 297-302.

(2) Douglas, S. M.; Dietz, H.; Liedl, T.; Högberg, B.; Graf, F.; Shih, W. M. Self-Assembly of DNA into Nanoscale Three-Dimensional Shapes. Nature 2009, 459, 414-418.

(3) Dietz, H.; Douglas, S. M.; Shih, W. M. Folding DNA into Twisted and Curved Nanoscale Shapes. Science 2009, 325, 725-730.

(4) Han, D.; Pal, S.; Nangreave, J.; Deng, Z.; Liu, Y.; Yan, H. DNA Origami with Complex Curvatures in Three-Dimensional Space. Science 2011, 332, 342-346.

(5) Ko, S.; Liu, H.; Chen, Y.; Mao, C. DNA Nanotubes as Combinatorial Vehicles for Cellular Delivery. Biomacromolecules 2008, 9, 3039-3043.

(6) Jiang, Q.; Song, C.; Nangreave, J.; Liu, X.; Lin, L.; Qiu, D.; Wang, Z.-G.; Zou, G.; Liang, X.; Yan, H.; Ding, B. DNA Origami as a Carrier for Circumvention of Drug Resistance. J. Am. Chem. Soc. 2012, 134, 13396-13403.

(7) Zhang, Q.; Jiang, Q.; Li, N.; Dai, L.; Liu, Q.; Song, L.; Wang, J.; Li, Y.; Tian, J.; Ding, B.; Du, Y. DNA Origami as an In Vivo Drug Delivery Vehicle for Cancer Therapy. ACS Nano 2014, 8, 6633-6643.

(8) Schüller, V. J.; Heidegger, S.; Sandholzer, N.; Nickels, P. C.; Suhartha, N. A.; Endres, S.; Bourquin, C.; Liedl, T. Cellular Immunostimulation by CpG-Sequence-Coated DNA Origami Structures. ACS Nano 2011, 5, 9696-9702.

(9) Douglas, S. M.; Bachelet, I.; Church, G. M. A Logic-Gated Nanorobot for Targeted Transport of Molecular Payloads. Science 2012, 335, 831-834. 
(10) Andersen, E. S.; Dong, M.; Nielsen, M. M.; Jahn, K.; Subramani, R.; Mamdouh, W.; Golas, M. M.; Sander, B.; Stark, H.; Oliveira, C. L. P.; Pedersen, J. S.; Birkedal, V.; Besenbacher, F.; Gothelf, K. V.; Kjems, J. Self-Assembly of a Nanoscale DNA Box with a Controllable Lid. Nature 2009, 459, 73-76.

(11) Langecker, M.; Arnaut, V.; Martin, T. G.; List, J.; Renner, S.; Mayer, M.; Dietz, H.; Simmel, F. C. Synthetic Lipid Membrane Channels Formed by Designed DNA Nanostructures. Science 2012, 338, 932-936.

(12) Burns, J. R.; Stulz, E.; Howorka, S. Self-Assembled DNA Nanopores That Span Lipid Bilayers. Nano Lett. 2013, 13, 23512356.

(13) Fu, J.; Liu, M.; Liu, Y.; Woodbury, N. W.; Yan, H. Interenzyme Substrate Diffusion for an Enzyme Cascade Organized on Spatially Addressable DNA Nanostructures. J. Am. Chem. Soc. 2012, 134, $5516-5519$.

(14) Voigt, N. V.; Tørring, T.; Rotaru, A.; Jacobsen, M. F.; Ravnsbæk, J. B.; Subramani, R.; Mamdouh, W.; Kjems, J.; Mokhir, A.; Besenbacher, F.; Gothelf, K. V. Single-Molecule Chemical Reactions on DNA Origami. Nat. Nanotechnol. 2010, 5, 200-203.

(15) Burns, J. R.; Lamarre, B.; Pyne, A. L. B.; Noble, J. E.; Ryadnov, M. G. DNA Origami Inside-Out Viruses. ACS Synth. Biol. 2018, 7, $767-773$.

(16) Castro, C. E.; Kilchherr, F.; Kim, D.-N.; Shiao, E. L.; Wauer, T.; Wortmann, P.; Bathe, M.; Dietz, H. A Primer to Scaffolded DNA Origami. Nat. Methods 2011, 8, 221-229.

(17) Keum, J.-W.; Bermudez, H. Enhanced Resistance of DNA Nanostructures to Enzymatic Digestion. Chem. Commun. 2009, 0, 7036-7038.

(18) Mei, Q.; Wei, X.; Su, F.; Liu, Y.; Youngbull, C.; Johnson, R.; Lindsay, S.; Yan, H.; Meldrum, D. Stability of DNA Origami Nanoarrays in Cell Lysate. Nano Lett. 2011, 11, 1477-1482.

(19) Kielar, C.; Xin, Y.; Shen, B.; Kostiainen, M. A.; Grundmeier, G.; Linko, V.; Keller, A. On the Stability of DNA Origami Nanostructures in Low-Magnesium Buffers. Angew. Chem., Int. Ed. 2018, 57, 94709474.

(20) Jahnen-Dechent, W.; Ketteler, M. Magnesium Basics. Clin. Kidney J. 2012, 5, i3-i14.

(21) Perrault, S. D.; Shih, W. M. Virus-Inspired Membrane Encapsulation of DNA Nanostructures To Achieve In Vivo Stability. ACS Nano 2014, 8, 5132-5140.

(22) Benson, E.; Mohammed, A.; Gardell, J.; Masich, S.; Czeizler, E.; Orponen, P.; Högberg, B. DNA Rendering of Polyhedral Meshes at the Nanoscale. Nature 2015, 523, 441-444.

(23) Veneziano, R.; Ratanalert, S.; Zhang, K.; Zhang, F.; Yan, H.; Chiu, W.; Bathe, M. Designer Nanoscale DNA Assemblies Programmed from the Top Down. Science 2016, 352, 1533-1534.

(24) Kiviaho, J. K.; Linko, V.; Ora, A.; Tiainen, T.; Järvihaavisto, E.; Mikkilä, J.; Tenhu, H.; Nonappa, N.; Kostiainen, M. A. Cationic Polymers for DNA Origami Coating - Examining Their Binding Efficiency and Tuning the Enzymatic Reaction Rates. Nanoscale 2016, $8,11674-11680$.

(25) Ponnuswamy, N.; Bastings, M. M. C.; Nathwani, B.; Ryu, J. H.; Chou, L. Y. T.; Vinther, M.; Li, W. A.; Anastassacos, F. M.; Mooney, D. J.; Shih, W. M. Oligolysine-Based Coating Protects DNA Nanostructures From Low-Salt Denaturation and Nuclease Degradation. Nat. Commun. 2017, 8, 15654.

(26) Wu, G. Y.; Wu, C. H. Receptor-Mediated In Vitro Gene Transformation by a Soluble DNA Carrier System. J. Biol. Chem. 1987, 262, 4429-4432.

(27) Lv, H.; Zhang, S.; Wang, B.; Cui, S.; Yan, J. Toxicity of Cationic Lipids and Cationic Polymers in Gene Delivery. J. Controlled Release 2006, 114, 100-109.

(28) Bloomfield, V. A. DNA Condensation by Multivalent Cations. Biopolymers 1997, 44, 269-282.

(29) Eisenberg, T.; Knauer, H.; Schauer, A.; Büttner, S.; Ruckenstuhl, C.; Carmona-Gutierrez, D.; Ring, J.; Schroeder, S.; Magnes, C.; Antonacci, L.; Fussi, H.; Deszcz, L.; Hartl, R.; Schraml, E.; Criollo, A.; Megalou, E.; Weiskopf, D.; Laun, P.; Heeren, G.;
Breitenbach, M.; et al. Induction of Autophagy by Spermidine Promotes Longevity. Nat. Cell Biol. 2009, 11, 1305-1314.

(30) Burak, Y.; Ariel, G.; Andelman, D. Onset of DNA Aggregation in Presence of Monovalent and Multivalent Counterions. Biophys. J. 2003, 85, 2100-2110.

(31) Pelta, J.; Livolant, F.; Sikorav, J.-L. DNA Aggregation Induced by Polyamines and Cobalthexamine. J. Biol. Chem. 1996, 271, 56565662.

(32) Qiu, X.; Andresen, K.; Lamb, J. S.; Kwok, L. W.; Pollack, L. Abrupt Transition from a Free, Repulsive to a Condensed, Attractive DNA Phase, Induced by Multivalent Polyamine Cations. Phys. Rev. Lett. 2008, 101, 3-6.

(33) Todd, B. A.; Parsegian, V. A.; Shirahata, A.; Thomas, T. J.; Rau, D. C. Attractive Forces between Cation Condensed DNA Double Helices. Biophys. J. 2008, 94, 4775-4782.

(34) Raspaud, E.; Durand, D.; Livolant, F. Interhelical Spacing in Liquid Crystalline Spermine and Spermidine-DNA Precipitates. Biophys. J. 2005, 88, 392-403.

(35) Andresen, K.; Qiu, X.; Pabit, S. A.; Lamb, J. S.; Hye, Y. P.; Kwok, L. W.; Pollack, L. Mono- and Trivalent Ions around DNA: A Small-Angle Scattering Study of Competition and Interactions. Biophys. J. 2008, 95, 287-295.

(36) Yoo, J.; Kim, H.; Aksimentiev, A.; Ha, T. Direct Evidence for Sequence-Dependent Attraction between Double-Stranded DNA Controlled by Methylation. Nat. Commun. 2016, 7, 11045.

(37) Hahn, J.; Wickham, S. F. J.; Shih, W. M.; Perrault, S. D. Addressing the Instability of DNA Nanostructures in Tissue Culture. ACS Nano 2014, 8, 8765-8775.

(38) Yoo, J.; Aksimentiev, A. In Situ Structure and Dynamics of DNA Origami Determined through Molecular Dynamics Simulations. Proc. Natl. Acad. Sci. U. S. A. 2013, 110, 20099.

(39) Luan, B.; Aksimentiev, A. DNA Attraction in Monovalent and Divalent Electrolytes. J. Am. Chem. Soc. 2008, 130, 15754-15755.

(40) Bignon, E.; Chan, C.-H.; Morell, C.; Monari, A.; Ravanat, J.-L.; Dumont, E. Molecular Dynamics Insights into Polyamine-DNA Binding Modes: Implications for Cross-Link Selectivity. Chem. - Eur. J. 2017, 23, 12845-12852.

(41) Elder, R. M.; Emrick, T.; Jayaraman, A. Understanding the Effect of Polylysine Architecture on DNA Binding Using Molecular Dynamics Simulations. Biomacromolecules 2011, 12, 3870-3879.

(42) Katz, A. M.; Tolokh, I. S.; Pabit, S. A.; Baker, N.; Onufriev, A. V.; Pollack, L. Spermine Condenses DNA, but Not RNA Duplexes. Biophys. J. 2017, 112, 22-30.

(43) Cheng, Y. Similarities and Differences in Interaction of $\mathrm{K}^{+}$and $\mathrm{Na}^{+}$with Condensed Ordered DNA. A Molecular Dynamics Computer Simulation Study. Nucleic Acids Res. 2006, 34, 686-696.

(44) Andresen, K.; Das, R.; Park, H. Y.; Smith, H.; Kwok, L. W.; Lamb, J. S.; Kirkland, E. J.; Herschlag, D.; Finkelstein, K. D.; Pollack, L. Spatial Distribution of Competing Ions around DNA in Solution. Phys. Rev. Lett. 2004, 93, 1-4.

(45) Das, R.; Mills, T. T.; Kwok, L. W.; Maskel, G. S.; Millett, I. S.; Doniach, S.; Finkelstein, K. D.; Herschlag, D.; Pollack, L. Counterion Distribution around DNA Probed by Solution X-Ray Scattering. Phys. Rev. Lett. 2003, 90, 4.

(46) Meisburger, S. P.; Pabit, S. A.; Pollack, L. Determining the Locations of Ions and Water around DNA from X-Ray Scattering Measurements. Biophys. J. 2015, 108, 2886-2895.

(47) Kornyshev, A. A.; Lee, D. J.; Leikin, S.; Wynveen, A. Structure and Interactions of Biological Helices. Rev. Mod. Phys. 2007, 79, 943996.

(48) Shklovskii, B. I. Screening of a Macroion by Multivalent Ions: Correlation-Induced Inversion of Charge. Phys. Rev. E: Stat. Phys., Plasmas, Fluids, Relat. Interdiscip. Top. 1999, 60, 5802-5811.

(49) Sushko, M. L.; Thomas, D. G.; Pabit, S. A.; Pollack, L.; Onufriev, A. V.; Baker, N. A. The Role of Correlation and Solvation in Ion Interactions with B-DNA. Biophys. J. 2016, 110, 315-326.

(50) Grosberg, A. Y.; Nguyen, T. T.; Shklovskii, B. I. Colloquium: The Physics of Charge Inversion in Chemical and Biological Systems. Rev. Mod. Phys. 2002, 74, 329-345. 
(51) Raspaud, E.; Olvera De La Cruz, M.; Sikorav, J. L.; Livolant, F. Precipitation of DNA by Polyamines: A Polyelectrolyte Behaviour. Biophys. J. 1998, 74, 381-393.

(52) Raspaud, E.; Chaperon, I.; Leforestier, A.; Livolant, F. Spermine-Induced Aggregation of DNA, Nucleosome, and Chromatin. Biophys. J. 1999, 77, 1547-1555.

(53) Tolokh, I. S.; Pabit, S. A.; Katz, A. M.; Chen, Y.; Drozdetski, A.; Baker, N.; Pollack, L.; Onufriev, A. V. Why Double-Stranded RNA Resists Condensation. Nucleic Acids Res. 2014, 42, 10823-10831.

(54) Tolokh, I. S.; Drozdetski, A. V.; Pollack, L.; Baker, N. A.; Onufriev, A. V. Multi-Shell Model of Ion-Induced Nucleic Acid Condensation. J. Chem. Phys. 2016, 144, 155101.

(55) Rouzina, I.; Bloomfield, V. A. Macroion Attraction Due to Electrostatic Correlation between Screening Counterions. 1. Mobile Surface-Adsorbed Ions and Diffuse Ion Cloud. J. Phys. Chem. 1996, 100, 9977-9989.

(56) Li, C. Y.; Hemmig, E. A.; Kong, J.; Yoo, J.; Hernández-Ainsa, S.; Keyser, U. F.; Aksimentiev, A. Ionic Conductivity, Structural Deformation, and Programmable Anisotropy of DNA Origami in Electric Field. ACS Nano 2015, 9, 1420-1433.

(57) Qiu, X.; Andresen, K.; Kwok, L. W.; Lamb, J. S.; Park, H. Y.; Pollack, L. Inter-DNA Attraction Mediated by Divalent Counterions. Phys. Rev. Lett. 2007, 99, 1-4.

(58) Qiu, X.; Kwok, L. W.; Park, H. Y.; Lamb, J. S.; Andresen, K.; Pollack, L. Measuring Inter-DNA Potentials in Solution. Phys. Rev. Lett. 2006, 96, 1-4.

(59) Shi, Z.; Castro, C. E.; Arya, G. Conformational Dynamics of Mechanically Compliant DNA Nanostructures from Coarse-Grained Molecular Dynamics Simulations. ACS Nano 2017, 11, 4617-4630.

(60) Chiu, T. K.; Dickerson, R. E. 1 A Crystal Structures of B-DNA Reveal Sequence-Specific Binding and Groove-Specific Bending of DNA by Magnesium and Calcium. J. Mol. Biol. 2000, 301, 915-945.

(61) Korolev, N.; Lyubartsev, A. P.; Laaksonen, A.; Nordenskiöld, L. On the Competition between Water, Sodium Ions, and Spermine in Binding to DNA: A Molecular Dynamics Computer Simulation Study. Biophys. J. 2002, 82, 2860-2875.

(62) Kang, H.; Yoo, J.; Sohn, B.-K.; Lee, S.-W.; Lee, H. S.; Ma, W.; Kee, J.-M.; Aksimentiev, A.; Kim, H. Sequence-Dependent DNA Condensation as a Driving Force of DNA Phase Separation. Nucleic Acids Res. 2018, 46, 9401-9413.

(63) Yoo, J.; Aksimentiev, A. The Structure and Intermolecular Forces of DNA Condensates. Nucleic Acids Res. 2016, 44, 2036-2046.

(64) Joo, C.; McKinney, S. A.; Lilley, D. M. J.; Ha, T. Exploring Rare Conformational Species and Ionic Effects in DNA Holliday Junctions Using Single-Molecule Spectroscopy. J. Mol. Biol. 2004, 341, 739751.

(65) Brady, R. A.; Kaufhold, W. T.; Brooks, N. J.; Foderà, V.; Di Michele, L. Flexibility Defines Structure in Crystals of Amphiphilic DNA Nanostars. J. Phys.: Condens. Matter 2019, 31, 074003.

(66) Douglas, S. M.; Marblestone, A. H.; Teerapittayanon, S.; Vazquez, A.; Church, G. M.; Shih, W. M. Rapid Prototyping of 3D DNA-Origami Shapes with CaDNAno. Nucleic Acids Res. 2009, 37, 5001-5006.

(67) Yoo, J.; AbderRahman, N. S.; Li, C.-Y.; Aksimentiev, A. Cadnano to PDB File Converter; nanoHUB, 2015. https://nanohub. org/resources/cadnanocvrt (accessed Oct 8, 2015).

(68) Jorgensen, W. L.; Chandrasekhar, J.; Madura, J. D.; Impey, R. W.; Klein, M. L. Comparison of Simple Potential Functions for Simulating Liquid Water. J. Chem. Phys. 1983, 79, 926-935.

(69) Humphrey, W.; Dalke, A.; Schulten, K. VMD: Visual Molecular

Dynamics. J. Mol. Graphics 1996, 14, 33-38.

(70) Phillips, J. C.; Braun, R.; Wang, W.; Gumbart, J.; Tajkhorshid, E.; Villa, E.; Chipot, C.; Skeel, R. D.; Kalé, L.; Schulten, K. Scalable Molecular Dynamics with NAMD. J. Comput. Chem. 2005, 26, 17811802.

(71) Hart, K.; Foloppe, N.; Baker, C. M.; Denning, E. J.; Nilsson, L.; MacKerell, A. D. Optimization of the CHARMM Additive Force Field for DNA: Improved Treatment of the BI/BII Conformational Equilibrium. J. Chem. Theory Comput. 2012, 8, 348-362.
(72) Yoo, J.; Aksimentiev, A. Improved Parametrization of $\mathrm{Li}^{+}, \mathrm{Na}^{+}$, $\mathrm{K}^{+}$, and $\mathrm{Mg}^{2+}$ Ions for All-Atom Molecular Dynamics Simulations of Nucleic Acid Systems. J. Phys. Chem. Lett. 2012, 3, 45-50.

(73) Yoo, J.; Aksimentiev, A. Improved Parameterization of AmineCarboxylate and Amine-Phosphate Interactions for Molecular Dynamics Simulations Using the CHARMM and AMBER Force Fields. J. Chem. Theory Comput. 2016, 12, 430-443.

(74) Martyna, G. J.; Tobias, D. J.; Klein, M. L. Constant Pressure Molecular Dynamics Algorithms. J. Chem. Phys. 1994, 101, 41774189.

(75) Michaud-Agrawal, N.; Denning, E. J.; Woolf, T. B.; Beckstein, O. MDAnalysis: A Toolkit for the Analysis of Molecular Dynamics Simulations. J. Comput. Chem. 2011, 32, 2319-2327.

(76) Levine, B. G.; Stone, J. E.; Kohlmeyer, A. Fast Analysis of Molecular Dynamics Trajectories with Graphics Processing UnitsRadial Distribution Function Histogramming. J. Comput. Phys. 2011, 230, 3556-3569. 